UDK: 655.3.022:004.9

DOI: $\underline{\text { https://doi.org/10.24867/07EF05Vasic }}$

\title{
ISPITIVANJE PONOVLJIVOSTI ŠTAMPE NA GRAFIČKOM SISTEMU KONICA MINOLTA BIZHUB C224E
}

\section{ANALYSIS OF PRINT REPEATABILITY ON PRINTING SYSTEM KONICA MINOLTA BIZHUB C224E}

\section{Marijana Vasić, Nemanja Kašiković, Rastko Milošević, Fakultet tehničkih nauka, Novi Sad}

\begin{abstract}
Oblast - GRAFIČKO INŽENJERSTVO I DIZAJN
Kratak sadržaj - Rad obuhvata teorijske osnove digitalne štampe $i$ istraživanje iste. Štampa test karti je vršena na tri podloge različite gramature. Za otiskivanje je korišćen grafički sistem Konica Minolta Bizhub C224E. Izvršena su objektivna merenja Lab vrednosti, optičke gustine, tonske vrednosti, beline $i$ žutoće papira $i$ preklapanje boja. Analizom dobijenih vrednosti kasnije je utvrđen kvalitet ponovljivosti štampe. Vršena je analiza vremenske ponovljivosti.
\end{abstract}

Ključne reči: Digitalna štampa, elektrofotografija, ponovljivost štampe

\begin{abstract}
This paper presents the bases of digital printing and research of it. The test card was printed on three different paper substrates. The Konica Minolta Bizhub C224E graphic system was used for printing. Measuring of Lab coordinate, optical density values, tone value increase, whiteness and yellowness of the paper and trapping was performed in order to calculate color differences. By analyzing those color differences, conclusions are made concerning print repeatability. Temporal repeatability analysis was performed.
\end{abstract}

Keywords: Digital printing, electrophotography, print repeatability

\section{UVOD}

Digitalna štampa je jedna od najmlađih tehnika štampe, a njen osnovni cilj je da se sam proces štampe pojednostavi u najvećoj mogućoj meri. Tehnologija digitalne štampe ne zavisi od pripreme odvojene ploče za svaku štampu. Sve boje se štampaju u jednom prolazu [1].

Mnogobrojni faktori utiču na kvalitet otiska, tako da kontrola kvaliteta predstavlja bitan deo štamparskog procesa kako bi dobili što kvalitetniji otisak. Preciznost prilikom štampe predstavlja jedan od bitnijih parametara, ali nije jedini parametar koji određuje kvalitet štampe.

Ponovljivost štampe je takođe bitan parametar. Taj parametar govori koliko je zapravo neki štamparski sistem konzistentan. Takođe, uz pomoć ovog parametra može da se utvrdi da li postoje neka odstupanja između otisaka istog tiraža, kao i između otisaka različitih tiraža za jedan isti proizvod.

\section{NAPOMENA:}

Ovaj rad proistekao je iz master rada čiji mentor je bio dr Nemanja Kašiković, vanr. prof.

\section{PONOVLJIVOST ŠTAMPE}

Ponovljivost i održanje kvaliteta tokom celog tiraža predstavlja jedan od najtežih zadataka koje digitalna štampa mora da ispuni. Nepostojanje fizičke štamparske forme je jedan od razloga zašto je ponovljivost težak zadatak. Kako se ta slika stvara iznova za svaki otisak, jasno je da je dobijanje identičnih kopija na ovaj način dosta teže [2].

Postoje dve vrste ponovljivosti. Prva predstavlja vremensku ponovljivost (temporal repeatability). Pored vremenske ponovljivosti, postoji i prostorna ponovljivost (spatial repeatability), koja se odnosi na ujednačenost elemenata koji se nalaze na različitim pozicijama na tabaku.

Preduslovi za kvalitetnu i ponovljivu štampu su kalibracija i profilisanje mašine za štampu. Kod elektrofotografske štampe, za postizanje ponovljivosti neophodno je:

- generisanje ujednačenog naelektrisanja fotoprovodnog cilindra pre oslikavanja,

- generisanje istih elektrostatičkih sila za prihvatanje tonera u fazi razvijanja,

- generisanje istih elektrostatičkih sila za prenos tonera sa fotoprovodnog cilindra na podlogu ili međuprenosač

- konzistentno čišćenje preostalih čestica tonera sa fotoprovodnog cilindra [3].

\section{EKSPERIMENTALNI DEO}

Eksperimentalni deo je započet tako što je test karta prikazana na slici 1 odštampana na tri različite ofsetne podloge. Materijal korišćen u eksperimentu je ofsetni papir od $80 \mathrm{~g} / \mathrm{m}^{2}, 90 \mathrm{~g} / \mathrm{m}^{2}$ i $120 \mathrm{~g} / \mathrm{m}^{2}$, pri čemu je za sve tri gramature papira test karta štampana $\mathrm{u}$ intervalu od 1 sat do 24 sata.

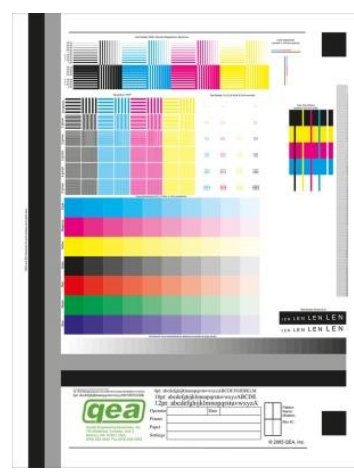

Slika 1. Test karta korišćena za potrebe istraživanja 
Ofsetni papir spada u jeftiniju klasu papira i namenjen je jednostavnoj štampi. Loša strana ofsetnog papira je njegova upojnost, pa štampa u boji deluje nezasićeno. Kako bi se okarakterisala podloga za štampu, merena je njena belina i žutoća, a zatim su vršena spektrofotometrijska merenja uz pomoć Techkom Spektrodens Premium koji je prikazan na slici 2. Ovaj refleksni spektrofotometar ima mogućnost proračunavanja svih denzitometrijskih veličina (porast tonske vrednosti, preklapanje boja, optička gustina, belina i žutoća), kao i kolorimetrijskih veličina (CIELab vrednosti). Štampa je vršena na digitalnoj štamparskoj mašini Konica Minolta Bizhub C224E, koja radi na principu elektrofotografije.

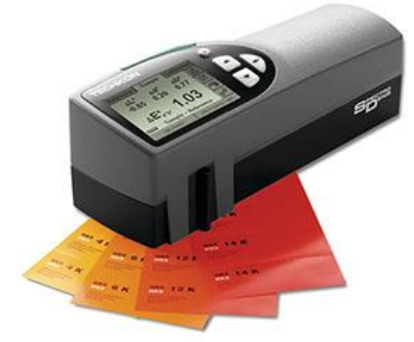

Slika 2. Techkon SpectroDens

\section{REZULTATI I DISKUSIJA}

Za svaku gramaturu papira odštampane su po tri test karte za vremenske intervale od 1 do 24 sata. U nastavku rada prikazani su rezultati merenja. $\mathrm{Na}$ osnovu optičke gustine dobija se svetliji ili tamniji ton boje. $\mathrm{Na}$ grafiku 1 prikazane su vrednosti boje za cijan, magentu, žutu, crnu, crvenu, zelenu i plavu boju za ofsetni papir od $90 \mathrm{~g} / \mathrm{m}^{2}$.

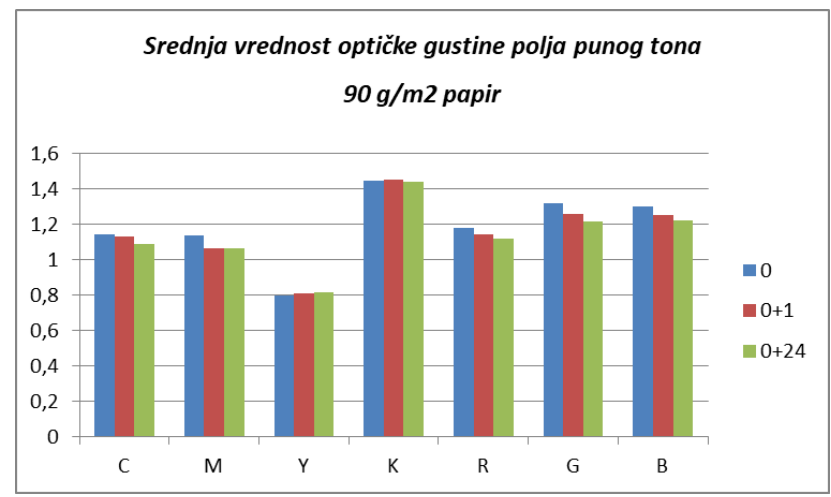

Grafik 1. Srednja vrednost optičke gustine polja punog tona $-90 \mathrm{~g} / \mathrm{m}^{2}$ papir

Upoređujući dobijene vrednosti, kod cijana, srednja vrednost opada od prvog otiska do otiska odštampanog nakon 24 sata. Što se tiče magente, vrednost je najveća kod prvog odštampanog otiska, dok je kod sledeća dva identična. Kod žute boje srednja vrednost raste u odnosu na prvi odštampani otisak, te je kod otiska nakon 24 sata najveća srednja vrednost. Kod crne boje uočava se da srednja vrednost raste pa zatim pada, dok kod crvene boje pada u odnosu na prvi odštampani otisak. Kod zelene i plave boje srednja vrednost opada.

$\mathrm{Na}$ grafiku 2 prikazane su srednje vrednosti optičke gustine za polje punog tona za ofsetni papir $80 \mathrm{~g} / \mathrm{m}^{2}$.
Upoređujući dobijene vrednosti, kod cijana, srednja vrednost opada od prvog otiska do otiska odštampanog nakon 24 sata. Što se tiče magente, vrednost je najveća kod prvog odštampanog otiska, i zatim opada. Kod žute boje srednja vrednost opada u odnosu na prvi odštampani otisak. Kod crne boje uočavamo da srednja vrednost opada, dok kod crvene boje je ista situacija kao i kod crne. Kod zelene i plave boje srednja vrednost opada takođe.

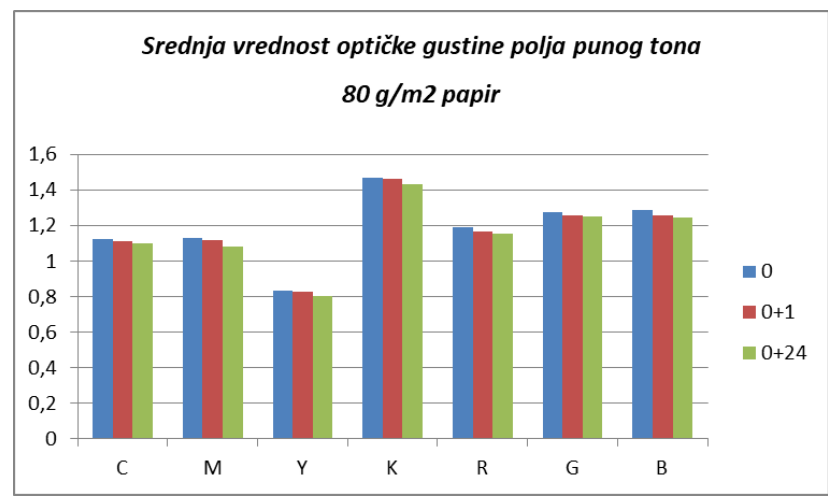

Grafik 2. Srednja vrednost optičke gustine polja punog tona $-80 \mathrm{~g} / \mathrm{m}^{2}$ papir

Na grafiku 3 prikazane su dobijene vrednosti za papir 120 $\mathrm{g} / \mathrm{m}^{2}$.

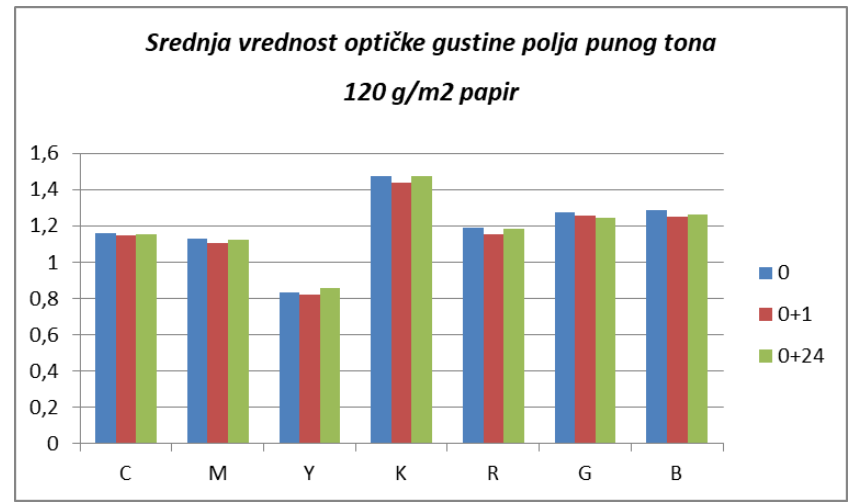

Grafik 3. Srednja vrednost optičke gustine polja punog tona $-120 \mathrm{~g} / \mathrm{m}^{2}$ papir

Upoređujući dobijene vrednosti, kod cijana, srednja vrednost raste od prvog otiska do otiska odštampanog nakon 24 sata. Što se tiče magente, vrednost je najveća kod prvog odštampanog otiska, i zatim opada i na kraju raste. Kod žute boje srednja vrednost opada, pa zatim raste. Kod crne boje uočava se da je srednja vrednost kod prvog otiska i otiska nakon 24 sata ista, ali kod otiska koji je dobijen nakon sat vremena vrednost je nešto manja. Kod crvene boje vrednost opada pa zatim raste. Kod zelene i plave boje srednja vrednost opada.

Belina i žutoća može da se meri na dva načina. Prvi način je objektivno merenje, dok je drugi subjektivno merenje. Belina i žutoća se mogu izmeriti uz pomoć spektrofotometra, ali pre samog merenja neophodno je uređaj kalibrisati na beloj pločici. Merenje beline i žutoće se vrši na delu papira gde ne postoje nikakvi tragovi štampe. Rezultati izmerene beline i žutoće za sve gramature prikazani su na grafiku 4. Podešavanja uređaja za belinu i žutoću su bila illiminant D65 i ugao 
posmatranja 100. Rezultati merenja za svaku gramaturu pokazuju to da papiri koji su korišćeni imaju najveću zastupljenost indeksa beline, dok je indeks žutoće veoma nizak.

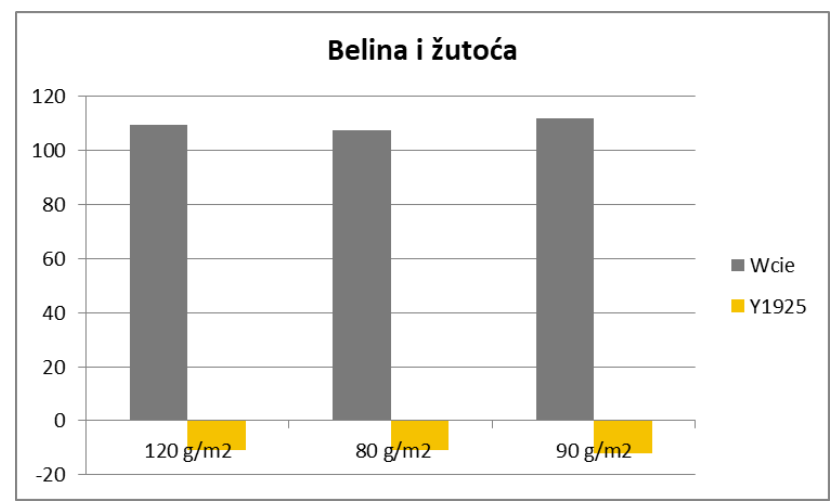

Grafik 4. Srednja vrednost beline i žutoće

Prilikom poređenja rezultata beline i žutoće između papira različite gramature uočava se da najveću vrednost beline, a najmanju vrednost žutoće ima papir od $90 \mathrm{~g} / \mathrm{m}^{2}$. Preklapanje boja je sposobnost da prva boja prihvati drugu boju na sebe. Uobičajan redosled štampanja je cijan, magenta, žuta, dok se crna boja štampa prva ili poslednja. Srednje vrednosti preklapanja boja za $90 \mathrm{~g} / \mathrm{m}^{2}$ su prikazane na grafiku 5 .

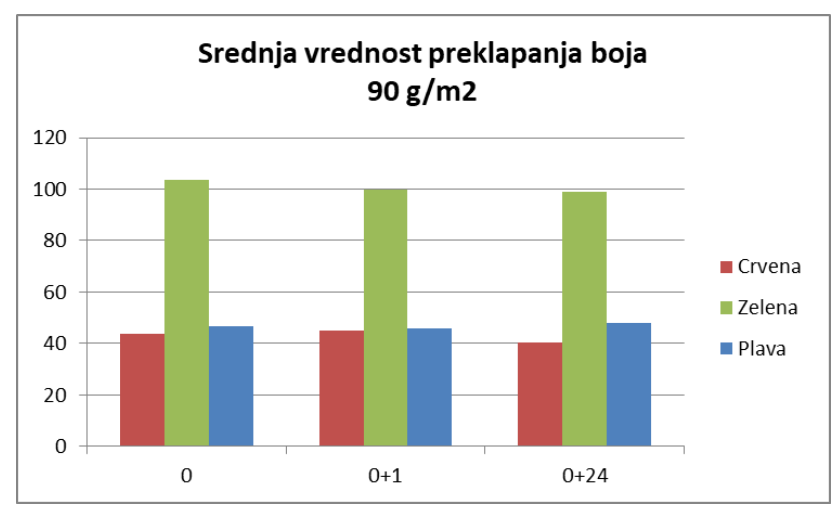

Grafik 5. Prikaz srednje vrednosti preklapanja boja $90 \mathrm{~g} / \mathrm{m}^{2}$ papir

Rezultati merenja pokazuju da je najmanja srednja vrednost za crvenu boju 40,23, a dok je najveća srednja vrednost 45 . Rezultati merenja na grafiku pokazuju da je najmanja srednja vrednost za zelenu boju 98,77, a dok je najveća srednja vrednost 103,40. Rezultati merenja pokazuju da je najmanja srednja vrednost za plavu boju 46,03 , a dok je najveća srednja vrednost 48,10. Rezultati srednjih vrednosti variraju u odnosu na odštampane otiske u $0,0+1$ i $0+24 h$, ali nema drastičnih odstupanja. Procenti preklapanja boja uglavnom opadaju kod uzoraka koji su štampani nakon prvog, sem kod crvene boje, gde vrednosti rastu. Kod uzoraka koji su odštampani 24 sata nakon prvog, vrednosti opadaju u odnosu na drugi odštampani uzorak, samo kod plave boje vrednosti rastu.

Na grafiku 6 prikazane su srednje vrednosti preklapanja za papir $80 \mathrm{~g} / \mathrm{m}^{2}$.

Rezultati merenja pokazuju da je najmanja srednja vrednost za crvenu boju 44,57, a dok je najveća srednja vrednost 46,10. Rezultati merenja pokazuju da je najmanja srednja vrednost za zelenu boju 100,97, a dok je najveća srednja vrednost 102,17 . Rezultati merenja na osnovu grafika broj 6 pokazuju da je najmanja srednja vrednost za plavu boju 48,53, a dok je najveća srednja vrednost 47,93. Rezultati srednjih vrednosti variraju u odnosu na odštampane otiske u $0,0+1$ i $0+24 \mathrm{~h}$, ali nema drastičnih odstupanja. Vrednosti preklapanja boja kod plave boje opadaju u odnosu na prvi odštampani otisak, dok kod crvene boje vrednosti preklapanja su najveće kod papira koji je odštampan sat vremena nakon prvog. Dok kod crvene boje, najmanja vrednost je kod otiska odštampanog sat vremena nakon prvog.

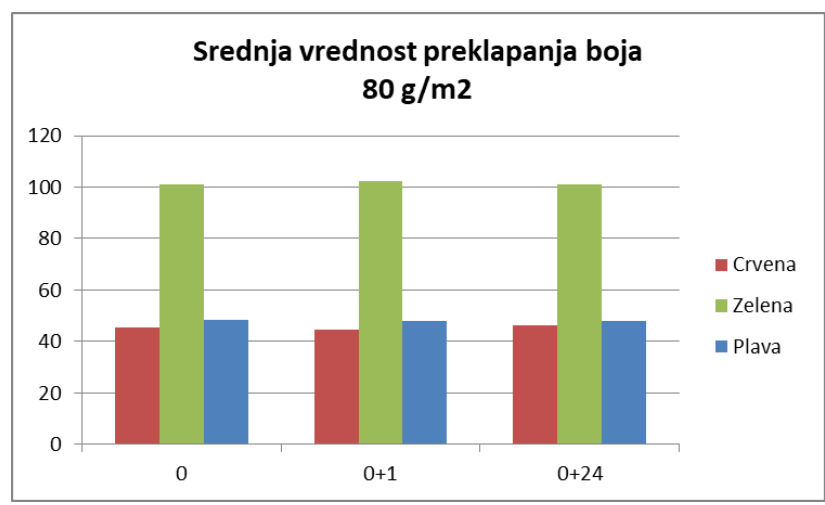

Grafik 6. Prikaz srednje vrednosti preklapanja boja $80 \mathrm{~g} / \mathrm{m}^{2}$ papir

$\mathrm{Na}$ grafiku 7 prikazane su srednje vrednosti za preklapanje boja kod ofset papira $120 \mathrm{~g} / \mathrm{m}^{2}$.

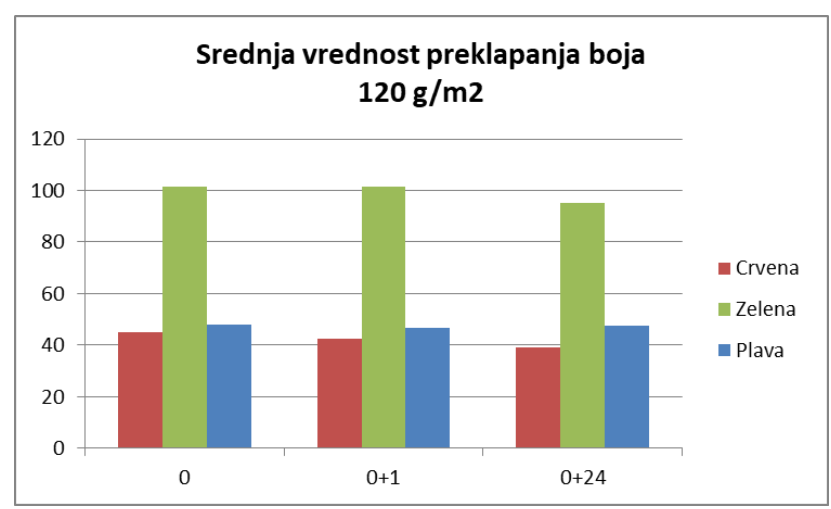

Grafik 7. Prikaz srednje vrednosti preklapanja boja $120 \mathrm{~g} / \mathrm{m}^{2}$ papir

Na osnovu grafika 7 zaključuje se da je najmanja srednja vrednost za crvenu boju 39,30, a dok je najveća srednja vrednost 45,03. Najmanja srednja vrednost za zelenu boju 95,17 , a dok je najveća srednja vrednost 101,33. Rezultati merenja pokazuju da je najmanja srednja vrednost za plavu boju 46,63, a dok je najveća srednja vrednost 47,87 . Rezultati srednjih vrednosti variraju $u$ odnosu na odštampane otiske u $0,0+1$ i $0+24 \mathrm{~h}$, ali nema drastičnih odstupanja. Vrednosti preklapanja kod crvene boje opadaju, dok kod zelene boje vrednost u $0+1$ je najveća, a kod plave boje u $0+1$ vrednost opada pa zatim raste. CIE Lab vrednosti se vrše na poljima punog tona za cijan, magentu, žutu, crnu, crvenu, zelenu i plavu boju. Kao i kod merenja beline i žutoće, bitno je izvršiti kalibraciju na beloj pločici. Ove dobijene vrednosti se koriste kako bi se izračunala razlika boja između prvog i drugog i prvog i trećeg uzorka i te vrednosti se koriste za poređenje. $\mathrm{Na}$ grafiku 8 prikazane su razlike boja na papiru $90 \mathrm{~g} / \mathrm{m}^{2}$. 


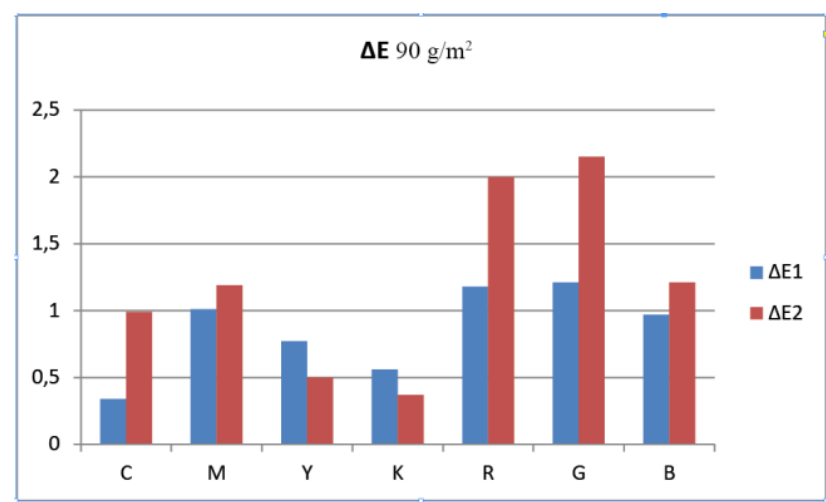

Grafik 8. Prikaz izračunatih razlika u boji na papiru od $90 \mathrm{~g} / \mathrm{m}^{2}$

Zaključuje se da je razlika boja veća između prvog i trećeg uzorka, sem kod žute i crne boje, gde je razlika veća između prvog i drugog uzorka.

Na grafiku 9 su prikazane razlike boja na papiru $80 \mathrm{~g} / \mathrm{m}^{2}$.

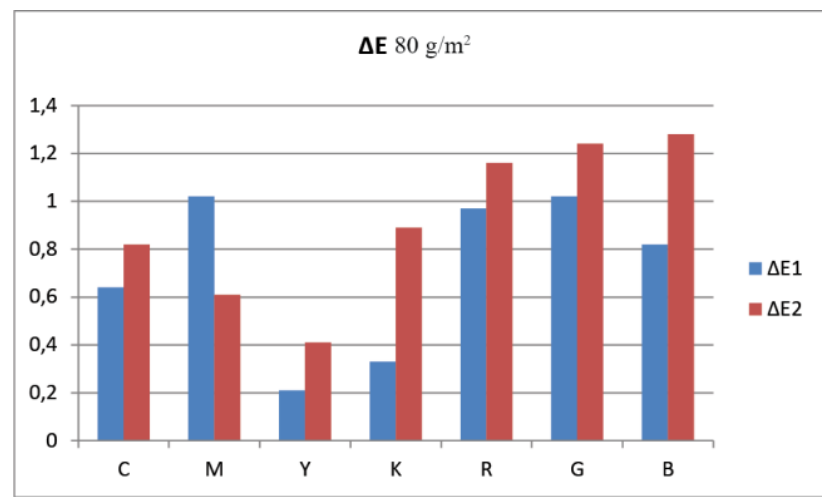

Grafik 9. Prikaz izračunatih razlika u boji na papiru od $80 \mathrm{~g} / \mathrm{m}^{2}$

Zaključuje se da je razlika boja veća između prvog i trećeg uzorka, sem kod magente gde je razlika veća između prvog i drugog uzorka.

$\mathrm{Na}$ grafiku 10 prikazane su vrednosti razlike boja kod papira $120 \mathrm{~g} / \mathrm{m}^{2}$.

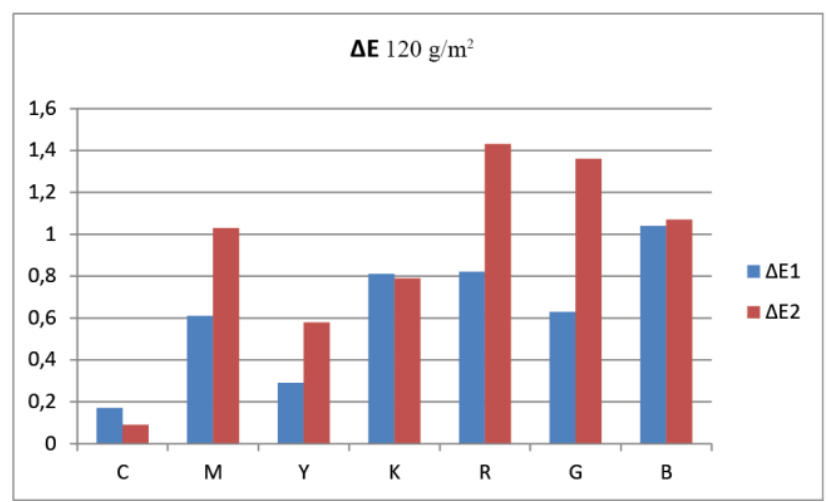

Grafik 9. Prikaz izračunatih razlika u boji na papiru od $120 \mathrm{~g} / \mathrm{m}^{2}$

\section{ZAKLJUČAK}

Cilj ovog rada bio je da se utvrdi ponovljivost štampe na štamparskom sistemu Konica Minolta Bizhub C224E, za tri podloge koje se razlikuju u gramaturi. Otisci su štampani na ofsetnom papiru od $80 \mathrm{~g} / \mathrm{m}^{2}, 90 \mathrm{~g} / \mathrm{m}^{2}$ i 120 $\mathrm{g} / \mathrm{m}^{2}$. Merile su se vrednosti optičke gustine punog tona, tonska vrednost, preklapanje boja, belina i žutoća papira i Lab vrednosti. Na osnovu izvršenih merenja uočava se da su odstupanja između dobijenih rezultata uglavnom minimalna, što ukazuje na dobru ponovljivost.

Kod preklapanja boja uočava se da zelena boja ima najveći procenat preklapanja $u$ odnosu na crvenu i plavu na svakoj gramaturi, a najmanji procenat preklapanja ima crvena.

Prilikom poređenja rezultata beline i žutoće između papira različite gramature uočava se da najveću vrednost beline, a najmanju vrednost žutoće ima papir od $90 \mathrm{~g} / \mathrm{m}^{2}$. Što se tiče optičke gustine, žuta boja ima najmanji nanos boje, dok ostale boje imaju minimalne varijacije.

Kod merenja CIE Lab vrednosti uočava se kod sve tri gramature da je razlika između prvog i trećeg uzorka uglavnom veća nego između prvog i drugog uzorka.

Kako bi se dobila što bolja ponovoljivost u štampi, potrebno je štamparske sisteme redovno kalibrisati prema preporukama proizvođača.

\section{LITERATURA}

[1] Novaković D., Kašiković N., (2013) Digitalna štampa, FTN Izdavaštvo, Novi Sad

[2] Kipphan H. (2001) Handbook of Print Media. 1st Ed. Berlin, Springer

[3] Sim T. P. (2009) Sensing and Control for Color Consistency of the Xerographic Printing Process. Doktorska disertacija. University of Minnesota [Online]Dostupno na: https://conservancy.umn.edu/handle/11299/56985 [Pristupljeno 05.10.2019.]

\section{Podaci za kontakt:}

\section{Marijana Vasić}

E-mail: marijanna95@yahoo.com

dr Nemanja Kašiković

E-mail: knemanja@uns.ac.rs

dr Rastko Milošević

E-mail: rastko.m@uns.ac.rs 